\title{
Bronchogenic Carcinoma
}

National Cancer Institute

\section{Source}

National Cancer Institute. Bronchogenic Carcinoma. NCI Thesaurus. Code C35875.

A lung carcinoma arising from the bronchial epithelium. 